\title{
Age modifies the genotype-phenotype relationship for the bitter receptor TAS2R38
}

\author{
Julie A Mennella, M Yanina Pepino, Fujiko F Duke, Danielle R Reed
}

\begin{abstract}
Background: The purpose of this study was to investigate the effect of TAS2R38 haplotypes and age on human bitter taste perception.

Results: Children (3 to $10 \mathrm{yrs}$ ), adolescents (11 to $19 \mathrm{yrs}$ ) and adults (mostly mothers, 20 to $55 \mathrm{yrs}(\mathrm{N}=980)$ were measured for bitter taste thresholds for 6-n-propylthiouracil (PROP) and genotyped for three polymorphisms of the AS2R38 gene (A49P, V262A, 1296V). Subjects were grouped by haplotype and age, as well as sex and race/ethnicity, and compared for PROP thresholds. Subjects with the same haplotype were similar in bitter threshold regardless of race/ethnicity (all ages) or sex (children and adolescents; all p-values $>0.05$ ) but age was a modifier of the genotype-phenotype relationship. Specifically, AVI/PAV heterozygous children could perceive a bitter taste at lower PROP concentrations than could heterozygous adults, with the thresholds of heterozygous adolescents being intermediate $(p<0.001)$. Similar age effects were not observed for subjects with the PAV/PAV or AVI/AVI homozygous haplotypes $(p>0.05)$ perhaps because there is less variation in taste perception among these homozygotes.

Conclusions: These data imply that the change in PROP bitter sensitivity which occurs over the lifespan (from bitter sensitive to less so) is more common in people with a particular haplotype combination, i.e., AVI/PAV heterozygotes.
\end{abstract}

\section{Background}

The experience of bitterness occurs after certain chemicals contact taste receptors located in cells on the surface of the tongue. Some investigators hypothesize that this sense provides information so that people do not ingest bitter-tasting toxic chemicals [1]. Potent poisons are found in many plants (e.g., like ricin and castor beans) which render them inedible [2]. However for many other plants, the potency or amount of toxin is low enough so that even though some (e.g., turnips or cabbage) might taste bitter, they can be eaten with fewer consequences [3]. However this poison detection system is not perfect because not everyone perceives the intensity of a fixed bitter stimulus in the same way $[4,5]$. The classic example of individual differences in taste sensitivity is for phenylthiocarbamide (PTC) and the related chemical propylthiouracil (PROP) [6]. Some people can detect these compounds at low concentrations, whereas others need much higher concentrations or cannot

* Correspondence: reed@monell.org

Monell Chemical Senses Center, 3500 Market St, Philadelphia PA, 19104, USA detect them at all $[7,8]$. Early family studies suggested this bimodality in taste response was due to alleles in a single gene $[8,9]$. Based on clues from many population studies, investigators predicted the minor allele frequency of the hypothetical locus would be high because bitter insensitivity to these compounds was common. They also predicted that the allele frequency would vary between human populations $[6,10]$. These predictions later proved to be accurate, with qualifications [11].

The gene which accounts for this taste trait is TAS2R38, a member of the family of taste receptors that respond to bitter stimuli [12-16] and the milestones of this discovery have recently been summarized [17]. One qualification to previous predictions mentioned above was that the molecular characterization of this genetic locus revealed three sites of genetic variation (A49P, $\mathrm{V} 262 \mathrm{~A}$, and $\mathrm{I} 296 \mathrm{~V}$ ) which are found in two common (AVI and PAV), two less common (AAI and AAV) and two rare haplotypes (PVI and PAI) [11,18-21]. Two haplotypes have not been observed in any subjects tested to date, AVV and PVV. As foreseen by earlier investigators, 
the frequency of the two common haplotypes varies by race/ethnicity $[11,18,19]$. Thus heterozygosity is common and may be due to balancing natural selection as a result of as yet unknown beneficial properties of the minor allele [18,22]. Another feature of this locus is that while homozygosity is associated with extremes of PROP threshold, heterozygosity is associated with a wide range of taste ability [12]. For a translation of genotype, haplotype and diplotype and their effects on taste perception for PROP, see Table 1.

Investigators have observed that younger subjects are more sensitive than older subjects to the bitterness of PROP or PTC, with some suggesting that age modifies the genotype-phenotype relationship [8,23-29]. Since allele frequencies do not differ between children and adults, the explanation for age-related differences in bitter perception must lie elsewhere. Previous investigators noted that people who were less sensitive to this class of bitter compounds seemed to lose their sensitivity faster as they got older, concluding that gene penetrance might differ by age and genotype [30,31]. To try to understand this issue, in an earlier study, we assessed children and their mothers $(\mathrm{N}=257)$ for the first genetic variant site (A49P) of the TAS2R38 gene and measured their PROP thresholds. We found that children who were heterozygous (AP) were more bitter sensitive than adults of the same genotype but that AA or PP homozygous children did not differ from adults of the same genotypes [32].

There were three unanswered questions that arose from this study. First, only the first variant site was typed. Thus, subjects who were homozygous for the A49 allele could have one of several haplotypes: (A)VI, (A)AI or (A)AV, and therefore some people classed as homozygous for the first allele (AA) would be heterozygous for the other alleles if the remaining haplotype was considered. This point is important because subjects with an AA haplotype have an intermediate phenotype [21]. Second, only children between the ages of 5 to 10 years and adults were studied so we could not determine when this change occurred. There were enough subjects to categorize people into three groups by genotype (AA, AP or PP at position +49) but too few to group by haplotype or diplotype. Therefore in the

Table 1 Translation of TAS2R38 genotypes/haplotypes/ diplotypes to PROP taste perception

\begin{tabular}{llllll}
\hline+49 & $\mathbf{+ 2 6 2}$ & $\mathbf{+ 2 9 6}$ & Haplotype & Diplotype & PROP Taste perception \\
\hline A & V & I & AVI & AVI/AVI & Nontaster \\
P & A & $V$ & PAV & PAV/PAV & Taster \\
\hline
\end{tabular}

Adapted from [11]. The terms 'taster' and 'nontaster' are used for convenience because there is a range of perceptual ability within each category. $+49,+262$ and +296 refer to amino acid locations in the TAS2R38 protein. The single letter notations refer to amino acids, e.g., $A=$ Alanine. present study, we phenotyped a large $(\mathrm{N}=980)$ and diverse group of children, adolescents and adults and genotyped them for three TAS2R38 alleles. These data now allow us to gauge the interaction between age and diplotype and the timing at which changes in gene penetrance for PROP bitter taste perception occurs.

\section{Results}

\section{Subjects}

Subjects who participated in research studies on taste and smell preferences during the years 2003-2007 were phenotyped for PROP threshold and genotyped for three alleles of the TAS2R38 gene. Included in this sample of 980 individuals were 448 children $(241 \mathrm{~F} / 207 \mathrm{M})$, 100 adolescents $(55 \mathrm{~F} / 45 \mathrm{M})$ and 432 adults $(425 \mathrm{~F} / 7 \mathrm{M})$. The majority of the adult subjects $(\mathrm{N}=345)$ were the mothers of the children or adolescent participants. Children ranged in age from 3 to 10 years (mean $7 \pm 2$ ), adolescents from 11-19 years (mean $15 \pm 2$ ) and adults from 20 to 55 years (mean $34 \pm 7$ ). Race/ethnicity was assigned by maternal (or adult) report according to standard US Census categories. We used the term race/ethnicity in describing our groups because it represents both the genetic and cultural components of this sample [33]. These categories reflect the population of the urban setting from which it was drawn: Philadelphia, Pennsylvania, USA; 56\% African-descent (Non-Hispanic; African-American), 29\% Caucasian (Non-Hispanic; Caucasian) and 15\% other groups (Mixed ancestry, Asian, or Hispanic). All testing procedures were approved by the Office of Regulatory Affairs at the University of Pennsylvania. Informed consent was obtained from each adult and assent was obtained from each child who was 7 years of age or older.

\section{Haplotypes and diplotypes}

A breakdown of diplotype frequency by age and race/ ethnicity is provided in Table 2. From all combinations of the three alleles, six out of the eight possible haplotypes and thirteen of the thirty-six possible diplotypes were observed. Two haplotypes accounted for over $84 \%$ of all haplotypes (AVI, 41.2\%, nontaster and PAV, $43.1 \%$, taster) whereas the remaining four haplotypes were rare (AAI, $12.2 \%$ and AAV, 3.3\%) or extremely rare (PAI, $<1 \%$ and $\mathrm{PVI},<1 \%$ ). The two remaining possible combinations, AVV and PVV, were not observed in this sample.

We refer to AVI as the 'nontaster' haplotype and PAV as the 'taster' haplotype for convenience, acknowledging that this use of terminology is an over-simplification. To make one further point of terminology, subjects with two copies of the taster or nontaster haplotype are referred to as having the taster or nontaster diplotype, respectively. The most frequent diplotype was the 
Table 2 Distribution of TAS2R38 diplotype by age and race/ethnicity

\begin{tabular}{|c|c|c|c|c|c|c|c|c|c|c|c|c|c|c|c|}
\hline Race & Age group & $\begin{array}{l}\mathrm{AVI} / \\
\mathrm{AVI}\end{array}$ & $\begin{array}{l}\mathrm{AAI} / \\
\mathrm{AVI}\end{array}$ & $\begin{array}{l}\text { AAV/ } \\
\text { AVI }\end{array}$ & $\begin{array}{l}\text { AAV/ } \\
\text { AAI }\end{array}$ & $\begin{array}{l}\text { AAI/ } \\
\text { AAI }\end{array}$ & $\begin{array}{l}\text { AAV/ } \\
\text { AAV }\end{array}$ & $\begin{array}{l}\text { AVI/ } \\
\text { PAV }\end{array}$ & $\begin{array}{l}\text { AAI/ } \\
\text { PAV }\end{array}$ & $\begin{array}{l}\text { AAV/ } \\
\text { PAV }\end{array}$ & $\begin{array}{l}\mathrm{AAI} / \\
\mathrm{PAI}\end{array}$ & $\begin{array}{l}\text { PAV/ } \\
\text { PVI }\end{array}$ & $\begin{array}{l}\text { PAV/ } \\
\text { PAI }\end{array}$ & $\begin{array}{l}\text { PAV/ } \\
\text { PAV }\end{array}$ & Total \\
\hline \multirow[t]{5}{*}{ Caucasian } & Children & 32 & 2 & 8 & 0 & 0 & 0 & 60 & 1 & 10 & 0 & 0 & 0 & 21 & 134 \\
\hline & Adolescents & 2 & 0 & 0 & 0 & 0 & 0 & 6 & 0 & 1 & 0 & 0 & 0 & 3 & 12 \\
\hline & Adults & 37 & 1 & 5 & 1 & 0 & 0 & 60 & 1 & 6 & 0 & 0 & 0 & 25 & 136 \\
\hline & Total & 71 & 3 & 13 & 1 & 0 & 0 & 126 & 2 & 17 & 0 & 0 & 0 & 49 & 282 \\
\hline & Percent & 25 & 1 & 5 & $<1$ & 0 & 0 & 45 & $<1$ & 6 & 0 & 0 & 0 & 18 & \\
\hline \multirow{5}{*}{$\begin{array}{l}\text { African- } \\
\text { American }\end{array}$} & Children & 35 & 26 & 2 & 0 & 7 & 0 & 73 & 39 & 5 & 0 & 0 & 1 & 44 & 232 \\
\hline & Adolescents & 8 & 10 & 0 & 1 & 6 & 0 & 22 & 15 & 1 & 0 & 1 & 0 & 7 & 71 \\
\hline & Adults & 31 & 29 & 4 & 0 & 9 & 0 & 86 & 37 & 10 & 1 & 1 & 0 & 37 & 245 \\
\hline & Total & 74 & 65 & 6 & 1 & 22 & 0 & 181 & 91 & 16 & 1 & 2 & 1 & 88 & 548 \\
\hline & Percent & 14 & 12 & 1 & $<1$ & 4 & 0 & 33 & 17 & 2 & $<1$ & $<1$ & $<1$ & 16 & \\
\hline \multirow[t]{5}{*}{ Other } & Children & 14 & 8 & 3 & 0 & 0 & 1 & 28 & 9 & 2 & 0 & 0 & 0 & 17 & 82 \\
\hline & Adolescents & 3 & 2 & 0 & 0 & 1 & 0 & 5 & 2 & 1 & 0 & 0 & 0 & 3 & 17 \\
\hline & Adults & 10 & 6 & 0 & 1 & 0 & 0 & 18 & 2 & 1 & 0 & 0 & 0 & 13 & 51 \\
\hline & Total & 27 & 16 & 3 & 1 & 1 & 1 & 51 & 13 & 4 & 0 & 0 & 0 & 33 & 150 \\
\hline & Percent & 18 & 11 & 2 & $<1$ & $<1$ & $<1$ & 34 & 9 & 3 & 0 & 0 & 0 & 22 & \\
\hline \multirow[t]{2}{*}{ All } & Total & 172 & 84 & 22 & 3 & 23 & 1 & 358 & 106 & 37 & 1 & 2 & 1 & 170 & 980 \\
\hline & Percent & 18 & 9 & 2 & $<1$ & 2 & $<1$ & 37 & 11 & 4 & $<1$ & $<1$ & $<1$ & 17 & \\
\hline
\end{tabular}

The number of children, adolescents, and adults by race/ethnicity and diplotype. Other = includes Asian, Hispanic and Mixed ancestry. The most common diplotypes are in bold text.

combination of the two most frequent haplotypes and these heterozygous subjects accounted for $37 \%$ of all subjects, followed in frequency by the homozygous subjects: 18\% (AVI/AVI, nontaster) and 17\% (PAV/PAV, taster). The remaining diplotypes were combinations of one rare and one common haplotype, except for three subjects, each of whom had a different combination of rare haplotypes.

Age effects are most apparent in heterozygous subjects A multinomial logistic regression was conducted and the results indicated a main effect of diplotype $\mathrm{X}^{2}{ }_{(6)}=323.62$, $\mathrm{p}<0.0000$, a trend toward an effect of age $\mathrm{X}^{2}{ }_{(6)}=12.29$, $\mathrm{p}=0.0557$ and a significant diplotype by age interaction $\left[\mathrm{X}^{2}{ }_{(9)}=22.62, \mathrm{p}=0.0071\right]$. When half of the heterozygous subjects were included in the analysis, to equate group sizes, the results were similar: a main effect of diplotype, $\mathrm{X}^{2}{ }_{(6)}=271.71, \mathrm{p}<0.0000$, no effect of age $\mathrm{X}^{2}{ }_{(6)}=3.67, \mathrm{p}=0.7200$ and a significant diplotype by age interaction $\left[\mathrm{X}^{2}{ }_{(9)}=19.36, \mathrm{p}=0.0223\right]$. To analyze the effects of age, independent of familial relationship, we conducted a similar analysis on a sub-sample of 508 unrelated people with the three most common diplotypes (AVI/AVI, AVI/PAV and PAV/PAV) and two age categories (children and adults) as fixed factors. Among unrelated individuals, there was a main effect of age $\mathrm{X}^{2}{ }_{(3)}=8.1, \mathrm{p}=0.04$; a main effect of diplotype, $\mathrm{X}_{(6)}^{2}=$
$180.3, \mathrm{p}<0.0000$ and an age by diplotype interaction $\mathrm{X}_{(6)}^{2}=17.1, \mathrm{p}=0.0070$.

To determine the nature of the diplotype by age interaction, groups were stratified by age group (children, adolescents and adults) within the most common diplotype groups (PAV/PAV, PAV/AVI, AVI/AVI) and percentages of subjects that could perceive bitterness at each concentration of PROP were compared. In a related analysis, we broadened the definition of heterozygotes to include subjects with one PAV haplotype and any other haplotype on the second chromosome (PAV/ $\left.\mathrm{A}^{* *}\right)$. As shown in Figure 1, age was a modifier of the genotype-phenotype relationship for heterozygous subjects. More heterozygous children perceived bitterness at the lowest concentrations than did adults with the same genotype, with adolescents intermediate between adults and children (AVI/PAV; omnibus, $\chi_{(4)}^{2}=16.44$, $\mathrm{p}=0.0025$; children and adolescents versus adults, $\chi_{(1)}^{2}$ $=12.86, \mathrm{p}=0.0003$; children versus adolescents and adults, $\left.\chi_{(1)}^{2}=16.10, \mathrm{p}<0.0001\right)$. PAV/PAV or AVI/AVI homozygous children, adolescents and adults did not differ in PROP thresholds (all p-values > 0.05). These results were similar when the broader definition of heterozygotes was used (PAV/A*; omnibus $\chi^{2}{ }_{(4)}=16.90$, $\mathrm{p}=0.0020$; children and adolescents versus adults, $\chi^{2}{ }_{(1)}$ $=11.88, \mathrm{p}=0.0006$; children versus adolescents and adults, $\left.\chi_{(1)}^{2}=15.46, \mathrm{p}=0.0001\right)$. 

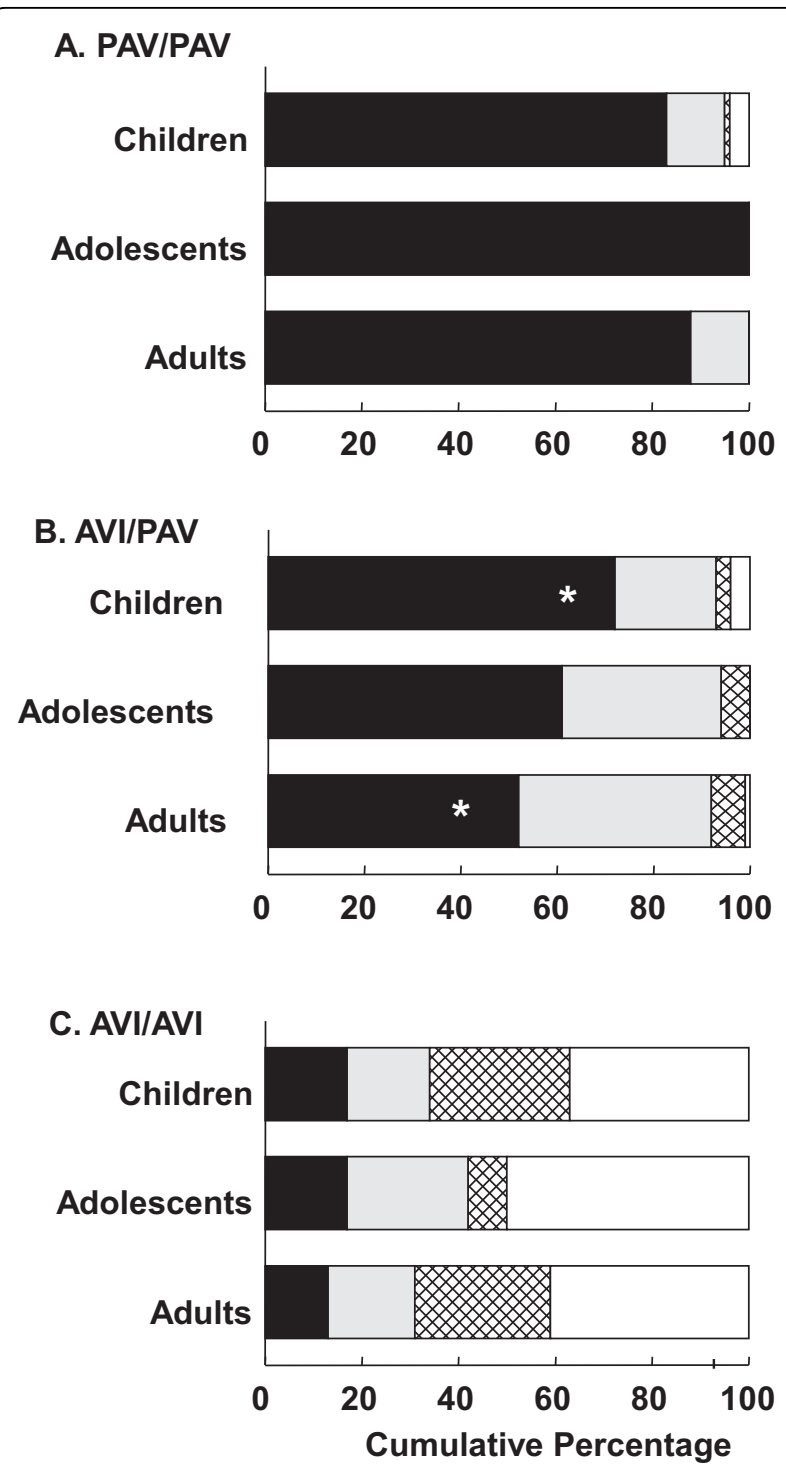

Figure 1 Effect of age group on PROP sensitivity by common diplotypes. The cumulative percentage of subjects with the following diplotypes (A) taster PAV/PAV, (B) heterozygous AVI/PAV, and (C) nontaster AVI/AVI who first reported a bitter taste when sampling 56 (black bars), 180 (grey bars), and $560 \mu \mathrm{M}$ PROP (hatched bars) or who never reported a bitter taste when sampling each of these PROP solutions (white bars). In panel (B) there is an increase in the proportion of children who report a bitter taste for the $56 \mu \mathrm{mol} /$ liter solution relative to adults. ${ }^{*}$ denotes a significant difference by $\chi^{2}$ partition.

Race/ethnicity and sex do not affect genotype-phenotype relationships

To determine whether race/ethnicity had independent effects on PROP thresholds, we focused on people with four haplotypes (PAV, AVI, AAI and AAV) and excluded those with the two rarest haplotypes (PAI and PVI; $N=4$ ) to meet the requirements of the statistical test. The frequencies of these four haplotypes differed between racial groups, specifically, the AAI haplotype was found more often in African-Americans whereas the AVI and AAV haplotypes were found more often in Caucasians (omnibus, $\chi^{2}{ }_{(6)}=123.10, \mathrm{p}<0.0000000$; partition for AAI, $\chi_{(1)}^{2}=105.02, \mathrm{p}<0.0000000$; partition for AVI $\chi_{(1)}^{2}=8.28, \mathrm{p}=0.00401$; partition for AAV, $\left.\chi_{(1)}^{2}=8.86, \mathrm{p}=0.00292\right)$.

Next, we determined whether there were race/ethnicity effects on PROP thresholds within the most common diplotype groups (AVI/AVI, AVI/PAV and PAV/ PAV). Other groups were excluded from this analysis, either because the contributing haplotypes were too rare for statistical comparisons or because the contributing haplotypes were specific to one racial group. We used a $\chi^{2}$ test when possible, but in the case of the PAV/PAV group, a proportion test was used to compare the most sensitive tasters (who perceived a bitter taste from PROP at the lowest concentration) with all other taste groups. This step was necessary because so few subjects with a PAV/PAV diplotype were insensitive to PROP. With these details in mind, within a diplotype, we found no differences between African-American and Caucasian subjects in PROP sensitivity (all p-values $>0.05$ ).

To determine whether sex had independent effects on PROP thresholds we focused on children and adolescents, groups with roughly equal numbers of boys and girls, because most of the people in the adult group were women (i.e., mothers). There were no sex differences in PROP thresholds in children and adolescents $\left(\chi_{(3)}^{2}=5.52, \mathrm{p}=0.137\right)$.

\section{Discussion}

The objective of this study followed from our previous study [32] and aimed to determine how age interacts with diplotype to affect PROP taste perception. While the association between TAS2R38 genotype and PROP taste sensitivity phenotype was resilient against effects of race/ethnicity (among all ages) and sex (in children in adolescents), age was a modifier of the association, especially among AVI/PAV heterozygotes. We found that children who were heterozygous for the common haplotypes were more sensitive to the bitterness of PROP than adults with the same diplotype, with adolescents intermediate. These findings are consistent with our earlier studies of children and their mothers which examined the effect of one TAS2R38 genotype (A49P) [32] as well as research of others who observed age-related changes in the perception of PTC and PROP [8,23-26,28,29]. The age effect was specific to diplotype and not detected among PAV/PAV homozygous taster or AVI/AVI homozygous nontaster subjects although this result might be partially explained by restricted range of phenotype of people with those homozygous diplotypes. Sample size differences which occur naturally 
between diplotype groups did not explain this effect because when groups were equated, the diplotype by age interaction was still evident. In addition, this result generalized to other heterozygous subjects because we observed it among subjects with rare heterozygous diplotypes (PAV/A**). Thus we conclude that these types of age-related changes in taste sensitivity are more pronounced in subjects with particular genotypes. This interaction between age and genotype is predicted to have a broad impact because many people in the population are heterozygous.

What causes the developmental shift in taste sensitivity among AVI/PAV heterozygotes is unknown. One explanation is that the age and diplotype interaction may be due to preferential allele expression, with children over-expressing the taster form rather than the nontaster form of the receptor early in life and then losing this tendency as they age. Adults heterozygous for the TAS2R38 gene do not express mRNA of each haplotype in a one-to-one proportion [12], so it is possible that heterozygous children might have a skewed expression pattern, perhaps over expressing the taster allele. If true, why this change would occur during adolescence is not known, but it may be triggered by signals that brain and body growth are complete [34]. The hypothesis that allelic expression could account for these phenotype differences is provocative, but necessarily speculative, because biopsy tissue of taste papillae of healthy children is not readily available for mRNA analysis. PROP bitterness is not entirely explained by alleles of the TAS2R38 gene [12,35-37] and these other modifiers (like taste papillae number) could be age-sensitive and more influential in heterozygous diplotypes [38].

Both the taster and nontaster alleles have been preserved since the time of the Neanderthals [39] and so it is presumed that both alleles must do important work $[22,40]$. Humans would not have encountered PROP or PTC in their natural environment but structurally related compounds are found normally in some plants [41] and these chemicals are potent thyroid toxins [3]. Thus it is likely that the benefit of the taster allele is to detect thyroid poisons [42]. However, the function of the nontaster allele, if any, is not known [17]. One piece of evidence that supports the hypothesis that the nontaster form has a function is that it has an intact reading frame and is not a pseudogene [11] and therefore it might be able to detect bitter molecules from a different chemical class [43]. Another point to consider is that taste receptors are also found in the gut and stimulate hormone secretion [44] and their expression is dependent on diet [44]. Bearing these ideas in mind, perhaps there is an evolutionary advantage to being heterozygous: the taster allele is dominant early in life when thyroid poisons can do the most harm while the nontaster allele (and its unknown function) is more dominant during adulthood.

The above hypothesis suggests that the age and genotype effects are specific to one particular bitter receptor but there is another possibility. Instead, we hypothesize that age may modify the genotype-phenotype relationship for other sensory receptors. Studies of olfactory genes in the mouse demonstrate that the pattern of gene expression changes during development, with receptor genes turning off forever early in life and others only turning on in adulthood [45]. Olfactory gene expression changes during development, so perhaps individual alleles might do so as well. Some evidence exists which is consistent with this hypothesis. Similar to the present finding with PROP perception, there are age-related declines in olfactory sensitivity for the musk odor androstenone, a change which occur around the time of puberty [46]. Alleles of a particular smell receptor predict the threshold to this odorant [47]. While it is not known if the decline in androstenone sensitivity is more common in heterozygotes, if this were the case, it would suggest that development by genotype effects may be a feature of other sensory receptors.

Although previous studies have found that females taste PROP and chemically related compounds at lower thresholds than males [6], we observed no sex effects in the children and adolescents studied here. This result is probably explained by sexual maturation, because half of our subjects were children and sex effects for this trait are not typically found until after puberty [6] and the adults were almost all women. Regarding race/ethnicity, allele frequencies for the TAS2R38 gene vary by racial/ ethnic group and therefore when two racial groups are compared, they differ in phenotype because they differ in genotype [18]. The differences in allele frequencies we found replicated those reported by others [11]. However we also asked a different question, which was whether race/ethnicity affects bitter threshold independent of genotype and here the answer was no. African American and Caucasian subjects with the same diplotype had indistinguishable bitter thresholds. Therefore differences in culture, experience and genetic background that are associated with race and ethnicity do not appear to modify this genotype-phenotype relationship.

Appropriate methods are critical in obtaining valid and reliable results when a wide age range of subjects is studied, so the rationale for the methods used herein should be considered. Bitter sensitivity to PROP and PTC have been assessed in the past in two ways (threshold versus intensity) and each method has several variations [26,48-50]. In this study, all subjects, regardless of age, were phenotyped the same way. A forced-choice categorization procedure enabled us to measure the 
lowest concentration at which they could recognize bitterness (threshold) rather than having them rate intensity. This method was chosen because children have difficulty with intensity measures and therefore threshold methods are preferable. This particular threshold method was developed by Anliker et al., (1994) and modified by Mennella et al., (2005) to specifically address several issues related to conducting research in pediatric populations, as follows: First, age-appropriate tasks which were fun and minimized the impact of language and cognitive development were used because young children are more prone to attention lapses and have shorter memory spans. Second, a forced-choice categorization procedure circumvents the element of uncertainty when tasting solutions at low concentrations. Furthermore, this method does not rely on 'yes' or 'no' answers which are prone to inaccuracy because young children tend to answer in the affirmative. Third, prior to the data collection and after a period of acclimation, we ascertained whether the child comprehended the task. Fourth, the same method was used for children, adolescents and adults so that any age-related differences observed were not due to disparity in the testing procedures. Albeit simple, this method proved to be reliable for children, adolescents and adults because subjects who were retested later demonstrate similar thresholds [32].

Children differ from adults since their likes and dislikes are the complex product of developing sensory systems, genetic variation, experiences and culture. In fact, they live in different worlds than adults in many sensory realms: sounds [51], smells [25,46], tastes [52] and irritants [53], but these differences are especially striking for bitter taste. In childhood, bitter sensitivity makes evolutionary sense because of the risk of accidental poisoning while foraging for plant foods, some of which may be poisonous [54]. But in the modern world, bitter sensitivity may take a toll on nutrition and health. An important example is that wholesome foods like vegetables are initially rejected, and this reluctance can later develop into a permanent avoidance because the positive aspects of the food are not experienced. Children need to be given repeated opportunities to learn to like bitter-tasting vegetables [55], maybe more so if they have bitter sensitive genotypes and the reluctance of parents and caregivers to offer foods that are initially rejected must be overcome [55]. Likewise, liquid formulations of medicines are avoided or refused by children because of their repellent taste $[56,57]$. Thus the rejection of unpalatable medications and bitter-tasting foods by children is a reflection of their basic biology and at least for vegetables can be fine-tuned by learning and genotype. A better understanding of the individual differences in chemosensory perception throughout the lifespan and the scientific basis for distaste and how to ameliorate it is a public health priority [56].

\section{Conclusion}

Our data suggest that bitter sensitivity for at least one stimulus, PROP, changes over the lifespan and is affected by the person's genotype for alleles with the bitter receptor $T A S 2 R 38$. These developmental sensory changes are most marked for people who have a particular haplotype combination, i.e., AVI/PAV heterozygotes.

\section{Method}

\section{Phenotyping for PROP perception}

To measure PROP perception, we used previously validated procedures that are sensitive to the cognitive limitations of pediatric populations [32]. Following a one-hour fast, each subject was tested individually in a closed room designed for sensory studies. Most of the children younger than 7 years were tested with their mothers present. The mothers, who sat behind the children and out of view, refrained from talking during the test session and listened to music with headphones to prevent them from hearing their children's answers. All other subjects were tested individually.

To allow for comparisons between the age groups, procedures were identical for all subjects and several steps were undertaken to make sure that the younger subjects understood the task before testing. The forcedchoice procedures and concentrations of PROP used were based on previous research [24,32]. Subjects were presented with a cup containing 5 milliliters of water and told to rinse the contents in their mouth and then spit it out. If the solution tasted like water, they were told to give it to a stuffed toy of Big Bird ${ }^{\mathrm{ma}}$ (a likeable, well-known television character puppet), but if it tasted "yucky" or bitter, they should give it to Oscar the Grouch, ${ }^{\mathrm{Tm}}$ so that he can "throw it in his trash can" [58]. The procedure was repeated and subjects tasted (but did not swallow), in ascending order, three solutions of PROP $(56,180$ and $560 \mu \mathrm{M})$ rinsing with water before and after each tasting. (If a subject swallowed the PROP solution, the testing was immediately discontinued). Subjects were classified into four groups based on the lowest concentration, if any, that they reported bitterness and, in turn, gave the sample to Oscar the Grouch. Those who gave all samples to Big Bird were classified as "None (of the samples) tasted bitter".

To determine the reliability of the method, PROP testing was conducted a second time on a random sample of 34 children and 22 adults. Testing occurred $9.2 \pm 1.3$ months after the initial test session. Reliability, which was assessed by conducting Kendall's tau (T) correlations, revealed that the grouping based on the PROP 
threshold data obtained during the initial session was significantly correlated with that obtained during the retest for both children (Kendall's $T=0.69$; $\mathrm{p}<0.05$ ) and adults (Kendall's $T=0.76 ; \mathrm{p}<0.05$ ). Twenty four of the children (71\%) and 15 of the adults (68\%) reported first perceiving a bitter taste at the same concentration as originally reported. Of the remaining 10 children, 8 reported a concentration one step below and 2 reported a concentration one step higher during the second test. Of the remaining 7 adults, 4 had thresholds one step below and 1 had a threshold two steps below the original.

\section{Genotyping and haplotyping for TAS2R38 gene}

Cells from the cheek were obtained using swabs and genomic DNA was extracted following the directions of the manufacturer (Epicenter, Madison, WI). Alleles of the TAS2R38 gene (Genbank accession no. NM_176817) were genotyped using real time PCR single nucleotide polymorphism (SNP) genotyping assays (rs713598, rs1726866 and rs10246939) with the Prism 7000, manufactured by Applied Biosystems (Foster City, CA). Haplotypes were identified by tracing the parental origin of the alleles when possible, or otherwise they were inferred by expectation-maximization methods using an algorithm implemented by the computer program fastPHASE [59].

\section{Data analyses}

We conducted a multinomial logistic regression analysis with three most common diplotypes (AVI/AVI, AVI/ $\mathrm{PAV}$ and PAV/PAV) and three age categories (children, adolescents, adults) as fixed factors and with a four-category outcome measure (subjects who first reported 56 $\mathrm{uM}, 180 \mathrm{uM}$ or $560 \mathrm{uM}$ PROP as bitter or subjects who reported that none of the solutions tasted bitter). The model was as follows: outcome measure = diplotype + age + diplotype $\times$ age. Analyses were re conducted after randomly removing heterozygous subjects to equate group sizes. If a significant interaction between diplotype and age were obtained, other methods outlined below were conducted to determine the nature of the interactions.

Most analyses followed the same method, which was to stratify subjects into groups by the variable of interest, and test for differences between the groups with an omnibus $\chi^{2}$ analyses for $k$ independent samples, followed by a partitioned $\chi^{2}$ to determine where the difference occurred [60]. This analysis cannot be undertaken if there are no observations in a particular cell, or when the number of observations in $20 \%$ of the cells is less than five, so in some cases, we conducted analysis only on groups with sufficient sample size, or we combined related groups to increase the sample size per cell.
(These conditions occasionally required that we do a test between two proportions rather than a $\chi^{2}$ ). To determine the effects of age, subjects were stratified by age and diplotype and the percentages of children, adolescents and adults who could taste PROP at each concentration were compared. We tested for race/ethnicity effects on PROP thresholds within particular diplotypes. For instance, we determined whether African-American subjects with the PAV/PAV diplotype had lower PROP thresholds than did Caucasians with the same diplotype. Subjects were also grouped by sex, to determine whether boys or girls differed in PROP thresholds, or by race/ethnicity, to determine whether these groups differed in haplotype frequency. Descriptive analyses, multinomial logistic regression and the proportion test were conducted with procedures in STATISTICA (StatSoft, Tulsa OK) and $\chi 2$ partitioning was calculated using a program described by Siegel and Castellan [60]. Criterion for statistical significance for all analyses was $\mathrm{p} \leq 0.05$.

\section{Abbreviations}

PTC: phenylthiocarbamide; PROP: propylthiouracil

\section{Acknowledgements}

We acknowledge the expert technical assistance of Kirsten J. Mascioli, Amanda H. McDaniel, Janice Kennedy, Greg Shaffer, Allison Steinmeyer, Dr. Catherine Forestell, Minna Bak, Sarah Obenrader, Macrina Cooper-White, Abigail Bosk and other technicians and students. Drs. Michael G. Tordoff, Paul A.S. Breslin and Gary K. Beauchamp commented on this manuscript prior to publication. Dr. Johannes Reisert assisted in language translation and Dr. Joseph H Lee provided statistical advice.

\section{Authors' contributions}

JAM designed, supervised data collection, supervised staff, analyzed data and wrote the manuscript. MYP collected and analyzed the data and assisted in manuscript preparation. FD collected and analyzed data and assisted in manuscript preparation. DRR supervised genotype data collection and co-wrote the manuscript. All authors read and approved the final manuscript.

\section{Authors' information}

This work was supported by the National Institutes of Health [HD37119, AA09523 to J.A.M. and DC004698 to D.R.R.)]; and a grant from the Pennsylvania Department of Health. The Pennsylvania Department of Health specifically disclaims responsibility for any analyses, interpretations, or conclusions. Dr. Pepino is currently a fellow through a National Institute of Drug Abuse training grant administered by the School of Medicine, Washington University in St. Louis, MO (\#T32 DA07313).

Received: 16 July 2009 Accepted: 1 July 2010 Published: 1 July 2010

\section{References}

1. Mueller KL, Hoon MA, Erlenbach I, Chandrashekar J, Zuker CS, Ryba NJ: The receptors and coding logic for bitter taste. Nature 2005, 434(7030):225-229.

2. Osborne $T$, Mendel $L$, Harris I: A study of the proteins of the castor bean, with special reference to the isolation of ricin. Am J Physiol 1903, XIV:259-286.

3. VanEtten C: Goitrogens. Toxic constituents of plant foodstuffs. Food science and technology New York: Academic PressLiener IE 1969, 103-142.

4. Kalmus H: Genetics of taste. Handbook of Sensory Physiology Berlin: SpringerBeidler LM 1971, 165-179. 
5. Fischer R, Griffin F: Quinine dimorphism: a cardinal determinant of taste sensitivity. Nature 1963, 200:343-347.

6. Guo SW, Reed DR: The genetics of phenylthiocarbamide perception. Ann Hum Biol 2001, 28(2):111-142.

7. Fox AL: The relationship between chemical constitution and taste. Proc Natl Acad Sci USA 1932, 18:115-120.

8. Blakeslee AF: Genetics of sensory thresholds: Taste for phenyl thio carbamide. Proc Natl Acad Sci USA 1932, 18:120-130.

9. Snyder LH: Inherited taste deficiency. Science 1931, 74:151-152.

10. Tills $D$, Kopec A, Tills $R$ : The distribution of the human blood groups, and other polymorphisms. Supplement 1. Oxford Oxfordshire: New York 1983.

11. Kim UK, Jorgenson E, Coon H, Leppert M, Risch N, Drayna D: Positional cloning of the human quantitative trait locus underlying taste sensitivity to phenylthiocarbamide. Science 2003, 299(5610):1221-1225.

12. Bufe B, Breslin PA, Kuhn C, Reed DR, Tharp CD, Slack JP, Kim UK, Drayna D, Meyerhof W: The molecular basis of individual differences in phenylthiocarbamide and propylthiouracil bitterness perception. Curr Biol 2005, 15(4):322-327.

13. Duffy VB, Davidson AC, Kidd JR, Kidd KK, Speed WC, Pakstis AJ, Reed DR, Snyder DJ, Bartoshuk LM: Bitter receptor gene (TAS2R38), 6-npropylthiouracil (PROP) bitterness and alcohol intake. Alcohol Clin Exp Res 2004, 28(11):1629-1637.

14. Prodi DA, Drayna D, Forabosco P, Palmas MA, Maestrale GB, Piras D, Pirastu $M$, Angius A: Bitter taste study in a sardinian genetic isolate supports the association of phenylthiocarbamide sensitivity to the TAS2R38 bitter receptor gene. Chem Senses 2004, 29(8):697-702.

15. Tepper BJ, Koelliker Y, Zhao L, Ullrich NV, Lanzara C, d'Adamo P, Ferrara A, Ulivi S, Esposito L, Gasparini P: Variation in the Bitter-taste Receptor Gene TAS2R38, and Adiposity in a Genetically Isolated Population in Southern Italy. Obesity (Silver Spring) 2008, 16:2289-2295.

16. Keller KL, Reid A, Macdougall MC, Cassano H, Lee Song J, Deng L, Lanzano P, Chung WK, Kissileff HR: Sex differences in the effects of inherited bitter thiourea sensitivity on body weight in 4-6-year-old children. Obesity (Silver Spring) 2009, 18:1194-1200.

17. Wooding S: Phenylthiocarbamide: a 75 -year adventure in genetics and natural selection. Genetics 2006, 172(4):2015-2023.

18. Wooding S, Kim UK, Bamshad MJ, Larsen J, Jorde LB, Drayna D: Natural selection and molecular evolution in PTC, a bitter-taste receptor gene. Am J Hum Genet 2004, 74(4):637-646.

19. Wang JC, Hinrichs AL, Bertelsen S, Stock H, Budde JP, Dick DM, Bucholz KK, Rice J, Saccone N, Edenberg HJ, Hesselbrock V, Kuperman S, Schuckit MA, Bierut LJ, Goate AM: Functional Variants in TAS2R38 and TAS2R16 Influence Alcohol Consumption in High-Risk Families of AfricanAmerican Origin. Alcohol Clin Exp Res 2007, 31(2):209-215.

20. Timpson NJ, Christensen M, Lawlor DA, Gaunt TR, Day IN, Ebrahim S, Davey Smith G: TAS2R38 (phenylthiocarbamide) haplotypes, coronary heart disease traits, and eating behavior in the British Women's Heart and Health Study. Am J Clin Nutr 2005, 81(5):1005-1011.

21. Timpson NJ, Heron J, Day IN, Ring SM, Bartoshuk LM, Horwood J, Emmett P, Davey-Smith G: Refining associations between TAS2R38 diplotypes and the 6-n-propylthiouracil (PROP) taste test: findings from the Avon Longitudinal Study of Parents and Children. BMC Genet 2007, 8(1):51.

22. Wooding S, Bufe B, Grassi C, Howard MT, Stone AC, Vazquez M, Dunn DM Meyerhof W, Weiss RB, Bamshad MJ: Independent evolution of bitter-taste sensitivity in humans and chimpanzees. Nature 2006, 440(7086):930-934.

23. Karam E Jr, Freire-Maia N: Phenylthiocarbamide and mental immaturity. Lancet 1967, 1(7490):622.

24. Anliker JA, Bartoshuk L, Ferris AM, Hooks LD: Children's food preferences and genetic sensitivity to the bitter taste of 6-n-propylthiouracil (PROP). Am J Clin Nutr 1991, 54:316-320.

25. Odeigah PG, Obieze AC: Differences in sodium chloride taste sensitivity in a rural and an urban population in Nigeria: implications for the incidence of hypertension. East Afr Med J 1986, 63(4):236-243.

26. Harris $\mathrm{H}$, Kalmus $\mathrm{H}$ : The measurement of taste sensitivity to phenylthiourea (P.T.C.). Annals of Eugenics 1949, 15:24-31.

27. Kaplan AR, Roland F: Taste sensitivity for bitterness: some biological and clinical implications. Recent advances in biological psychiatry New York: Plenum PressWortis J 1965, 183-196

28. Kalmus H, Trotter WR: Direct assessment of the effect of age on P.T.C. sensitivity. Ann Hum Genet 1962, 26:145-149.
29. Ehrhardt VS: Vergleichende Geschmacksprufung von PTC und Conteben. Homo 1952, 3:153-162.

30. Whissell-Buechy D: Effects of age and sex on taste sensitivity to phenylthiocarbamide (PTC) in the Berkeley Guidance sample. Chem Senses 1990, 15(1):39-57.

31. Glanville EV, Kaplan AR, Fischer R: Age, Sex, and Taste Sensitivity. J Gerontol 1964, 19:474-478

32. Mennella JA, Pepino MY, Reed DR: Genetic and environmental determinants of bitter perception and sweet preferences. Pediatrics 2005, 115(2):e216-222

33. Sankar P, Cho MK: Genetics. Toward a new vocabulary of human genetic variation. Science 2002, 298(5597):1337-1338.

34. Coldwell SE, Oswald TK, Reed DR: A marker of growth differs between adolescents with high vs. low sugar preference. Physiol Behav 2009, 96(4-5):574-580.

35. Reed DR, Nanthakumar E, North M, Bell C, Bartoshuk LM, Price RA Localization of a gene for bitter-taste perception to human chromosome 5p15. Am J Hum Genet 1999, 64(5):1478-1480.

36. McAnally HM, Poulton R, Hancox RJ, Prescott J, Welch D: Psychosocial correlates of 6-n-propylthiouracil (PROP) ratings in a birth cohort. Appetite 2007, 49(3):700-703.

37. Chandrashekar J, Mueller KL, Hoon MA, Adler E, Feng L, Guo W, Zuker CS, Ryba N: T2Rs function as bitter taste receptors. Cell 2000, 100:703-711.

38. Hayes JE, Bartoshuk LM, Kidd JR, Duffy VB: Supertasting and PROP bitterness depends on more than the TAS2R38 gene. Chem Senses 2008, 33:255-265.

39. Lalueza-Fox C, Gigli E, de la Rasilla M, Fortea J, Rosas A: Bitter taste perception in Neanderthals through the analysis of the TAS2R38 gene. Biol Lett 2009, 5:809-1.

40. Fischer RA, Ford EB, Huxley J: Taste testing the anthropoid apes. Nature 1939, 144:750.

41. Boyd WC: Taste reactions to antithyroid substances. Science 1950 112(2901):153

42. Sandell MA, Breslin PA: Variability in a taste-receptor gene determines whether we taste toxins in food. Curr Biol 2006, 16(18):R792-794.

43. Henkin Rl, Gillis WT: Divergent taste responsiveness to fruit of the tree Antidesma bunius. Nature 1977, 265(5594):536-537.

44. Jeon TI, Zhu B, Larson JL, Osborne TF: SREBP-2 regulates gut peptide secretion through intestinal bitter taste receptor signaling in mice. J Clin Invest 2008, 118(11):3693-3700.

45. Zhang X, Rogers M, Tian H, Zhang X, Zou DJ, Liu J, Ma M, Shepherd GM, Firestein $\mathrm{SJ}$ : High-throughput microarray detection of olfactory receptor gene expression in the mouse. Proc Natl Acad Sci USA 2004, 101(39):14168-14173

46. Dorries KM, Schmidt HJ, Beauchamp GK, Wysocki CJ: Changes in sensitivity to the odor of androstenone during adolescence. Dev Psychobiol 1989, 22(5):423-435

47. Keller A, Zhuang H, Chi Q, Vosshall LB, Matsunami H: Genetic variation in a human odorant receptor alters odour perception. Nature 2007, 449(7161):468-472

48. Lawless $\mathrm{H}$ : A comparison of different methods used to assess sensitivity to the taste of propylthiocarbamide. Chem Senses Flavour 1980, 5:247-256.

49. Tepper BJ, Christensen CM, Cao J: Development of brief methods to classify individuals by PROP taster status. Physiol Behav 2001, 73(4):571-577.

50. Bartoshuk LM, Duffy VB, Miller IJ: PTC/PROP tasting: Anatomy, psychophysics, and sex effects. Physiol Behav 1994, 56:1165-1171.

51. Schneider BA, Trehub SE, Morrongiello BA, Thorpe LA: Developmental changes in masked thresholds. J Acoust Soc Am 1989, 86(5):1733-1742.

52. Desor JA, Greene LS, Maller O: Preferences for sweet and salty in 9- to 15-year-old and adult humans. Science 1975, 190:686-687.

53. Patil S, Maibach HI: Effect of age and sex on the elicitation of irritant contact dermatitis. Contact Dermatitis 1994, 30(5):257-264.

54. Liener IE: Toxic constituents of plant foodstuffs. New York: Academic Press, 2 1980.

55. Forestell CA, Mennella JA: Early determinants of fruit and vegetable acceptance. Pediatrics 2007, 120(6):1247-1254.

56. Mennella JA, Beauchamp GK: Optimizing oral medications for children. Clin Ther 2008, 30(11):2120-2132.

57. Glendinning Jl: Is the bitter rejection response always adaptive? Physiol Behav 1994, 56(6):1217-1227. 
58. Schmidt HJ, Beauchamp GK: Adult-like odor preferences and aversions in three-year-old children. Child Dev 1988, 59(4):1136-1143.

59. Scheet $P$, Stephens M: A fast and flexible statistical model for large-scale population genotype data: applications to inferring missing genotypes and haplotypic phase. Am J Hum Genet 2006, 78(4):629-644.

60. Siegel S, Castellan NJ: Nonparametric statistics for the behavioral sciences. Boston: McGraw Hill 1988

doi:10.1186/1471-2156-11-60

Cite this article as: Mennella et al:: Age modifies the genotype-

phenotype relationship for the bitter receptor TAS2R38. BMC Genetics 2010 11:60

Submit your next manuscript to BioMed Central and take full advantage of:

- Convenient online submission

- Thorough peer review

- No space constraints or color figure charges

- Immediate publication on acceptance

- Inclusion in PubMed, CAS, Scopus and Google Scholar

- Research which is freely available for redistribution

Submit your manuscript at www.biomedcentral.com/submit 